\title{
Corrigendum: Neuronal and hormonal perturbations in postural tachycardia syndrome
}

\author{
Philip L. Mar and Satish R. Raj* \\ Departments of Medicine and Pharmacology, Vanderbilt University School of Medicine, Nashville, TN, United States
}

Keywords: postural tachycardia syndrome, aldosterone, angiotensin II, blood volume, hyperadrenergic activity, Autonomic Nervous System, neuropathy, orthostatic intolerance

\section{A Corrigendum on}

Neuronal and hormonal perturbations in postural tachycardia syndrome by Mar, P. L., and Raj, S. R. (2014). Front. Physiol. 5:220. doi: 10.3389/fphys.2014.00220

OPEN ACCESS

Edited and reviewed by:

Ovidiu Constantin Baltatu,

Anhembi Morumbi University, Brazil

*Correspondence:

Satish R. Raj

satish.raj@ucalgary.ca

Specialty section:

This article was submitted to

Integrative Physiology,

a section of the journal

Frontiers in Physiology

Received: 21 May 2019

Accepted: 11 July 2019

Published: 30 July 2019

Citation:

Mar PL and Raj SR (2019)

Corrigendum: Neuronal and hormonal perturbations in postural tachycardia syndrome. Front. Physiol. 10:978. doi: 10.3389/fphys.2019.00978
There was an error in the original article. A reference to low-frequency R-R interval variability was made instead of high frequency R-R interval variability. Furthermore, it was incorrectly stated that decreased cardiovagal activation and its contribution to POTS is unclear, while it should have stated that it may contribute to POTS.

A correction has been made to the section Pathophysiology of POTS (Table 1), subsection Hyperadrenergic POTS, paragraph five:

"There is also some data that the parasympathetic system may contribute to the tachycardia in POTS. Furlan et al. reported that high frequency R-R interval variability $(0.15-0.4 \mathrm{~Hz})$, a marker of parasympathetic activity, was reduced in POTS patients compared to healthy subjects during passive orthostatism (Furlan et al., 1998). Thus, decreased cardiovagal activation due to reduced parasympathetic nervous system activity may contribute to POTS."

The authors apologize for this error and state that this does not change the scientific conclusions of the article in any way. The original article has been updated.

\section{REFERENCES}

Furlan, R., Jacob, G., Snell, M., Robertson, D., Porta, A., Harris, P., et al. (1998). Chronic orthostatic intolerance: a disorder with discordant cardiac and vascular sympathetic control. Circulation 98, 2154-2159.

Copyright (ङ 2019 Mar and Raj. This is an open-access article distributed under the terms of the Creative Commons Attribution License (CC BY). The use, distribution or reproduction in other forums is permitted, provided the original author(s) and the copyright owner(s) are credited and that the original publication in this journal is cited, in accordance with accepted academic practice. No use, distribution or reproduction is permitted which does not comply with these terms. 